\title{
Results from a Spanish national survey on the application of ultrasound in pulmonology services
}

\author{
Cristina Ramos-Hernández ${ }^{*^{*}}$ (D) Maribel Botana-Rial ${ }^{1}$, Rosa Cordovilla-Pérez ${ }^{2}$, Manuel Núñez-Delgado ${ }^{1}$ and \\ Alberto Fernández-Villar ${ }^{1}$
}

\begin{abstract}
Background: This was an observational, cross-sectional, and multicentre study carried out from October to December 2020, through a survey sent to Spanish Society of Pulmonology and Thoracic Surgery members in public hospitals with different levels of complexity. Our objective was to complete a national analysis of clinical practice, organisation, infrastructure, the services portfolio, teaching, and research activity related to ultrasound.

Results: Data from 104 hospitals were analysed. Ultrasound was used in $56.7 \%$ of cases, both in the area of bronchopleural techniques and on conventional wards, with no differences between centres. Lung ultrasound (LUS) was performed more often in the procedures area in intermediate-complexity centres compared to high- and low-complexity centres (36\% vs. 31\% and 6.25\%, respectively). More high-complexity centres had three or more ultrasound scanners than intermediate-complexity centres (38\% vs. 16\%); $43 \%$ of low-complexity centres shared their ultrasound equipment with other specialties. Fewer than $6 \%$ of centres did not have an ultrasound machine. LUS was most often used during the treatment of pleural effusion (91.3\%), in the differential diagnosis of dyspnoea (51.9\%), and to rule out iatrogenic pneumothorax (50.9\%). Only 5.7\% of the centres had a pulmonologist specialised in LUS. Finally, fewer than $35 \%$ of the hospitals were teaching centres and fewer than 18\% participated in research projects.

Conclusions: The use and availability of LUS has grown in pulmonology services, however, still relatively few pulmonologists are specialised in its use. Moreover, teaching and research activity in this field is scarce. Strategies are necessary to improve physicians' skill at using LUS and to promote its use, with the ultimate goal of improving healthcare activity.
\end{abstract}

Keywords: Ultrasound, LUS, Pulmonology, Survey

\section{Background}

The use of ultrasound in pulmonology services is evident, not only because of the increase in its indications but also because of the number of specialists who have incorporated it into their daily clinical practice. Although,

\footnotetext{
*Correspondence: cristina.ramos.hernandez@sergas.es

${ }^{1}$ Department of Pneumology, Hospital Alvaro Cunqueiro, Neumo Vigo I

+ I. Institute of Health Research Galicia South (IISGS), Xerencia de Xestión integrada de Vigo, C/Clara Campoamor 341, 36312 Vigo, Pontevedra, Spain

Full list of author information is available at the end of the article
}

ultrasound initially started to be used as a guide during pleural procedures [1], over time it has proven useful in the assessment of the lung parenchyma, diaphragm, and chest wall, and it has became a basic first-line tool to establish a differential diagnosis in patients with dyspnoea $[2,3]$. The use of ultrasound by pulmonologists has also extended to the evaluation of the lower limbs [4], vocal chords [5], and even for performing echocardiography [6] at the patient's bedside to obtain data that may be useful in the diagnosis of pulmonary pathologies. Lung ultrasound (LUS) is a technique performed in bronchopleural procedures units and in intermediate 
respiratory care units, but its use in conventional hospital floor settings or in pneumology consultations is not as well established.

It is important to understand the degree to which ultrasound is used in the field of pulmonology at the national level to help researchers to detect potential difficulties in further developing this technique and to create recommendations or training programs that target the fields that need them the most, which helps physicians to achieve higher quality care. Thus, we carried out this study to evaluate the current situation in clinical settings and to address the issues set out above. Our main objective was to describe current clinical care practices regarding the use of ultrasound and to collect data related to its use in pulmonology services, organisational and infrastructural factors, the portfolio of services available, and ultrasound teaching and research activity.

\section{Methods \\ Design}

From October to December 2020, we carried out a crosssectional, national level, multicentre study through a survey sent to every member of the Spanish Society of Pulmonology and Thoracic Surgery (SEPAR) working in hospitals with different levels of complexity. The latter factor was evaluated considering the criteria used in other national studies [7]. High-complexity centres were considered as those with a large technological endowment, more than 500 beds, and 160-300 medical intern residents (MIRs); intermediate-complexity centres were those with 200-500 beds and more than 50 MIRs; and low-complexity centres had fewer than 200 hospital beds and/or fewer than 50 MIRs.

Every pulmonologist and MIR in this specialty who were SEPAR members and who may be involved in the routine use of LUS (in hospital wards, consultations, intermediate respiratory care units, or bronchopleural procedures area) were sent the study survey. Privately managed centres and those located outside the national territory were excluded. When responses were obtained from several professionals from the same centre, the answers from the first participant were recorded.

Using a methodology similar to one our group has previously employed in a similar study [7], SEPAR members were contacted with the questionnaire by email and asked to complete it using an online platform. The survey included a total of 21 items, four of them designed to assess technological resources and the organisation and infrastructure available for LUS (Table 1), 12 items aimed to assess the portfolio of services available using this technique (Table 2), and five items were used to understand the centre's involvement in teaching, training, and research related to ultrasound (Table 3 ).

\section{Statistical analysis}

Qualitative variables were expressed as absolute frequencies and percentages. Comparisons between study groups were made according to the level of care provided at the hospital centre and the association between qualitative variables was evaluated with Chi-squared tests $\left(\chi^{2}\right)$. The outcomes from all the statistical comparisons were considered significant when the probability of error was less than $5 \%$. The data processing and analysis was carried out using SPSS software (v21, IBM Corp., Armonk, NY, USA).

\section{Ethical factors}

Due to the nature of this study, neither informed consent nor approval by the Research Ethics Committee was required. The collection, treatment, and conservation of the data was carried out anonymously in accordance with the current provisions of the General Data Protection Regulation (EU Regulation 2016-679 of the European Parliament and Council, of April 27, 2016) and Spanish regulations on the protection of personal data.

\section{Results}

\section{Sample description}

A total of 155 health professionals belonging to 109 hospital centres responded to the survey. The results from three centres were excluded, because they were not located in the national territory and two other centres were excluded, because they were privately managed. Thus, data from 104 publicly managed hospitals were analysed in this work, of which 58 (55.8\%) were highly complex centres, $30(28.8 \%)$ were of intermediate complexity, and 16 (15.4\%) were low-complexity centres.

\section{Results related to organisation and infrastructure}

We found significant differences in the availability of ultrasound machines depending on the complexity of the care provided at the centre. The pneumology service in high-complexity centres more often had at least 3 ultrasound scanners compared to low-complexity centres ( $37.9 \%$ vs. $0 \% ; p=0.008)$, with the latter being more likely to share an ultrasound system with other services $(43.7 \%$ vs. $13.3 \%$ vs. $3.4 \%$, respectively; $p=0.0001$ ). We found no differences between the different levels of care in terms of the availability of different types of transducers; $35.5 \%$ of the centres surveyed had 3 types of transducer (convex, linear, and sector), $41.3 \%$ had linear and convex transducers, and $20 \%$ only had one type, usually a convex transducer (66.6\%). LUS was routinely used (in $56.7 \%$ of cases) both in the bronchopleural procedures area and in the hospital ward, with no differences between the centre types. However, high- and intermediate-complexity 
Table 1 Organisational and infrastructural factors related to the use of ultrasound

\begin{tabular}{|c|c|c|c|c|}
\hline Organisation and infrastructure & Total $N=104$ & $\begin{array}{l}\text { High- } \\
\text { complexity } \\
\text { centre } N=58\end{array}$ & $\begin{array}{l}\text { Intermediate- } \\
\text { complexity centre } \\
N=30\end{array}$ & $\begin{array}{l}\text { Low- } \\
\text { complexity } \\
\text { centre } N=16\end{array}$ \\
\hline \multicolumn{5}{|l|}{ Availability of ultrasound scanners } \\
\hline $\begin{array}{l}\text { Two exclusive-use ultrasound scanners are available in the pneumology } \\
\text { service }\end{array}$ & $24 / 104(23.0 \%)$ & 17/58 (29.3\%) & $5 / 30(16.6 \%)$ & $2 / 16(12.5 \%)$ \\
\hline $\begin{array}{l}\text { Three or more exclusive-use ultrasound scanners are available in the } \\
\text { pneumology service }\end{array}$ & $27 / 104(25.9 \%)$ & $22 / 58(37.9 \%)^{\mathrm{a}}$ & $5 / 30(16.6 \%)$ & $0 / 16(0 \%)$ \\
\hline An ultrasound system is shared with other services & $13 / 104(12.5 \%)$ & $2 / 58(3.4 \%)^{\mathrm{a}}$ & $4 / 30(13.3 \%)^{b}$ & $7 / 16(43.7 \%)$ \\
\hline Only one ultrasound machine is available in the pulmonology service & $34 / 104(32.6 \%)$ & $14 / 58(2.1 \%)$ & $14 / 30(46.6 \%)$ & $6 / 16(37.5 \%)$ \\
\hline No ultrasound scanner is available in the pulmonology service & $6 / 104(5.7 \%)$ & $2 / 58(3.4 \%)$ & $2 / 30(6.6 \%)$ & $1 / 16(6.25 \%)$ \\
\hline \multicolumn{5}{|l|}{ Probe availability } \\
\hline A linear, convex, and sector probe is available & $37 / 104(35.5 \%)$ & 23/58 (39.6\%) & $9 / 30(30 \%)$ & $5 / 16(31.2 \%)$ \\
\hline A linear and convex probe is available & $43 / 104(41.3 \%)$ & 26/58 (44.8\%) & $11 / 30(36.6 \%)$ & $6 / 16(37.5 \%)$ \\
\hline Only one probe is available & $21 / 104(20.1 \%)$ & $9 / 58(15.5 \%)$ & $8 / 30(26.6 \%)$ & $4 / 16(25 \%)$ \\
\hline Linear & $3 / 21$ & $1 / 9$ & - & $2 / 4$ \\
\hline Convex & $13 / 21$ & $4 / 9$ & $7 / 8$ & $2 / 4$ \\
\hline Microconvex & $2 / 21$ & $2 / 9$ & - & - \\
\hline Sectorial & $3 / 21$ & $2 / 9$ & $1 / 8$ & - \\
\hline \multicolumn{5}{|l|}{ New applications } \\
\hline Elastography is available & 14/104 (13.4\%) & 9/58 (15.5\%) & $3 / 30(10 \%)$ & $2 / 16(12.5 \%)$ \\
\hline \multicolumn{5}{|l|}{ Elastography type } \\
\hline Strain & $6 / 104(5.7 \%)$ & $4 / 58(6.8 \%)$ & $1 / 30(3.3 \%)$ & $1 / 16(6.2 \%)$ \\
\hline SWE & 0/104 (0\%) & $0 / 58(0 \%)$ & $0 / 30(0 \%)$ & $0 / 16(0 \%)$ \\
\hline Both & $8 / 104(7.6 \%)$ & $5 / 58(6.89 \%)$ & $2 / 30(6.6 \%)$ & $1 / 16(6.2 \%)$ \\
\hline \multicolumn{5}{|l|}{ Elastography probe } \\
\hline Linear & $2 / 104(1.9 \%)$ & $1 / 58(1.7 \%)$ & $0 / 30(0 \%)$ & $1 / 16(6.2 \%)$ \\
\hline Convex & $5 / 104(4.8)$ & $3 / 58(5.1 \%)$ & $2 / 30(6.6 \%)$ & $0 / 16(0 \%)$ \\
\hline Both & $7 / 104(6.7 \%)$ & $5 / 58(8.6 \%)$ & $1 / 30(3.6 \%)$ & $1 / 16(6.2 \%)$ \\
\hline EBUS elastography is available & $13 / 104(12.5 \%)$ & $11 / 58(18.9 \%)$ & $1 / 30(3.3 \%)$ & $1 / 16(6.25 \%)$ \\
\hline \multicolumn{5}{|l|}{ Dedicated LUS staff } \\
\hline LUS is performed only in the bronchopleural procedures area & $30 / 104(28.8 \%)$ & 18/58 (31.0\%) & $11 / 30(36.6 \%)^{b}$ & $1 / 16(6.25 \%)$ \\
\hline $\begin{array}{l}\text { LUS is performed in the bronchopleural procedures area and in the } \\
\text { hospital ward on a routine basis }\end{array}$ & $59 / 104(56.7 \%)$ & $32 / 58(55.1 \%)$ & $17 / 30(56.6 \%)$ & $10 / 16(62.5 \%)$ \\
\hline A person specialised in performing LUS is available & $6 / 104(5.7 \%)$ & $4 / 58(6.8 \%)$ & $0 / 30(0 \%)$ & $2 / 16(12.5 \%)$ \\
\hline
\end{tabular}

Data expressed as absolute frequencies (\%)

SWE shear wave, LUS lung ultrasound, EBUS endobronchial ultrasound

${ }^{a} p<0.05$ high-complexity compared to low-complexity centres

${ }^{\mathrm{b}} p<0.05$ intermediate-complexity compared to low-complexity centres

care centres more often performed LUS exclusively in the bronchopleural procedures area compared to lowcomplexity centres ( $31 \%$ vs. $6.25 \%, p=0.09$ and $36.6 \%$ vs. $6.25 \%, p=0.04$, respectively). New ultrasonography techniques such as elastography were available in $13.4 \%$ of the centres, regardless of the level of care provided (Table 1 , Fig. 1).

\section{Results related to the ultrasound service portfolio}

LUS was most often used to evaluate pleural effusion (91.3\%), to determine a differential diagnosis between pulmonary pathologies (51.9\%), and to rule out iatrogenic pneumothorax after completing a broncho-pleural procedure (50.9\%). The least common uses for LUS were for the evaluation of vocal cord dysfunction $(3.8 \%)$ and the use of elastography to study masses (7.6\%) and pleural effusions (5.7\%). We only found significant differences for this item regarding the use of LUS for the diagnosis and/ or follow-up of interstitial lung diseases (ILD) in low-vs. medium-complexity centres ( $31.2 \%$ vs. $3.3 \%, p=0.02)$, and when performing lower limb (LL) ultrasound for suspected thromboembolic disease, which more often 


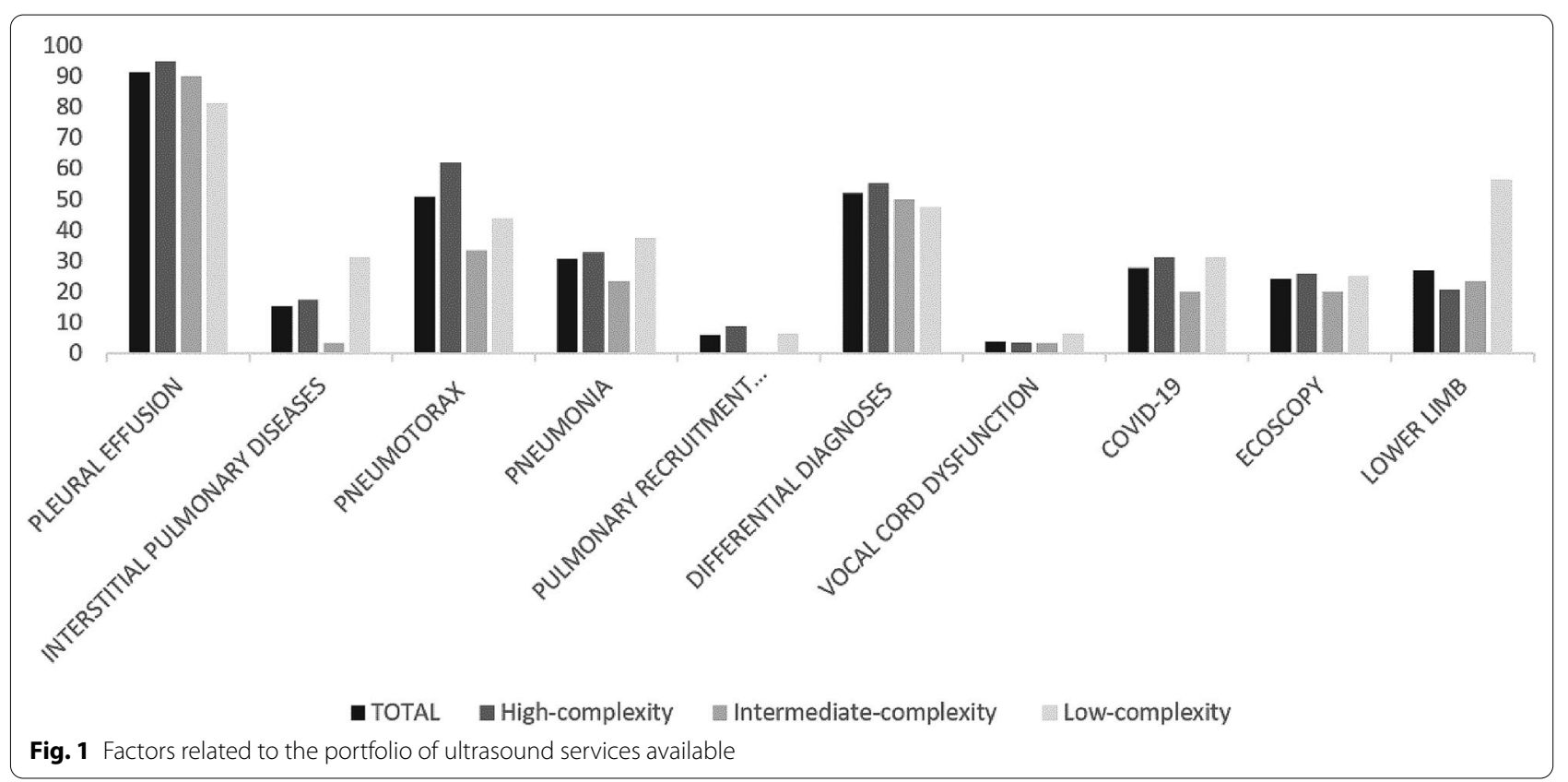

presented at low-complexity centres compared to intermediate $(56.2 \%$ vs. $23.3 \%, p=0.05)$ or high-complexity centres ( $56.2 \%$ vs. $20.6 \%, p=0.01)$ (Table 2 ).

\section{Results related to teaching, training, and research}

Overall, $34.6 \%$ and $30.7 \%$ of the centres taught undergraduate and postgraduate courses related to LUS and physicians in up to $17.3 \%$ of the centres were undertaking research projects related to LUS. In this sense, we only found significant differences in the number of multicentre research projects related to TE carried out at highcomplexity centres vs. low-complexity centres $(25.8 \%$ vs. $0 \%, p=0.05)$.

Table 2 Factors related to the portfolio of ultrasound services available

\begin{tabular}{|c|c|c|c|c|}
\hline SERVICES PORTFOLIO & Total $N=104$ & $\begin{array}{l}\text { High- } \\
\text { complexity } \\
\text { centre } N=58\end{array}$ & $\begin{array}{l}\text { Intermediate- } \\
\text { complexity centre } \\
N=30\end{array}$ & $\begin{array}{l}\text { Low-complexity } \\
\text { centre } N=16\end{array}$ \\
\hline LUS is routinely used to diagnose and manage PLEURAL EFFUSION & $95 / 104(91.3 \%)$ & $55 / 58(94.8 \%)$ & $27 / 30(89.9 \%)$ & $13 / 16(81.2 \%)$ \\
\hline $\begin{array}{l}\text { LUS is routinely used to diagnose and/or follow-up INTERSTITIAL PUL- } \\
\text { MONARY DISEASES }\end{array}$ & $16 / 104(15.3 \%)$ & $10 / 58(17.2 \%)$ & $1 / 30(3.3 \%)^{b}$ & $5 / 16(31.2 \%)$ \\
\hline $\begin{array}{l}\text { LUS is routinely used to rule out IATROGENIC PNEUMOTORAX after } \\
\text { bronchopleural procedures }\end{array}$ & $53 / 104(50.9 \%)$ & $36 / 58(62.0 \%)$ & $10 / 30(33.3 \%)$ & $7 / 16(43.7 \%)$ \\
\hline LUS is routinely used for the diagnosis and/or follow-up of PNEUMONIA & $32 / 104(30.7 \%)$ & $19 / 58(32.7 \%)$ & $7 / 30(23.3 \%)$ & $6 / 16(37.5)$ \\
\hline $\begin{array}{l}\text { LUS is routinely used to guide PULMONARY RECRUITMENT MANEU- } \\
\text { VERS }\end{array}$ & $6 / 104(5.9 \%)$ & $5 / 58(8.6 \%)$ & $0(0 \%)$ & $1 / 16(6.25 \%)$ \\
\hline $\begin{array}{l}\text { LUS is routinely used to resolve DIFFERENTIAL DIAGNOSES between } \\
\text { different pulmonary pathologies }\end{array}$ & $54 / 104(51.9 \%)$ & $32 / 58(55.1 \%)$ & $15 / 30(49.9 \%)$ & $7 / 16(43.7 \%)$ \\
\hline LUS is routinely used to assess VOCAL CORD DYSFUNCTION & 4/104 (3.8\%) & $2 / 58(3.4 \%)$ & $1 / 30(3.3 \%)$ & $1 / 16(6.25 \%)$ \\
\hline LUS is routinely used to diagnose and follow-up patients with COVID-19 & $29 / 104(27.8 \%)$ & $18 / 58(31.0 \%)$ & $6 / 30(20 \%)$ & $5 / 16(31.2 \%)$ \\
\hline $\begin{array}{l}\text { ECOSCOPY is used for LVEF estimation, to measure cavities, for pericardial } \\
\text { assessment, and to calculate the TAPSE }\end{array}$ & $25 / 104(24.0 \%)$ & $15 / 58(25.8 \%)$ & $6 / 30(20 \%)$ & $4 / 16(25 \%)$ \\
\hline $\begin{array}{l}\text { LL ultrasound is routinely performed when thromboembolic disease } \\
\text { is suspected }\end{array}$ & $28 / 104(26.9 \%)$ & $12 / 58(20.6 \%)^{a}$ & $7 / 30(23.3 \%)^{b}$ & $9 / 16(56.2 \%)$ \\
\hline ELASTOGRAPHY is used to assess masses & $8 / 104(7.6 \%)$ & $7 / 58(12.1 \%)$ & $0(0 \%)$ & $1 / 16(6.2 \%)$ \\
\hline ELASTOGRAPHY is used to assess pleural effusions & $6 / 104(5.7 \%)$ & $4 / 58(6.8 \%)$ & $1 / 30(3.3 \%)$ & $1 / 16(6.2 \%)$ \\
\hline
\end{tabular}

LL lower limb, COVID-19 coronavirus SARS-CoV2, LVEF left ventricular ejection fraction, TAPSE tricuspid annular plane systolic excursión

${ }^{a} p<0.05$ high-complexity compared to low-complexity centres

${ }^{\mathrm{b}} p<0.05$ intermediate-complexity compared to low-complexity centres 


\section{Discussion}

This is the first study at a state level to assess the degree to which LUS is used by pulmonologist in Spain. Our data showed that LUS is widely used to study the pathologies for which it was first developed, but that training in new indications (for which never exceeded 65\%) is required.

The assessment of pleural effusions showed the most consolidated use of LUS (91.3\%), with the use of ultrasound improving the results obtained in this healthcare field compared to previous years. After the safety alert issued by the United Kingdom in 2008 [8] when a series of iatrogenic complications caused by the insertion of chest drains was identified, in 2010, the British Thoracic Society (BTS) recommended performing all pleural procedures with ultrasound guidance [9]. Nonetheless, a 2014 survey completed by 500 pulmonologists [10] found that up to $35 \%$ of LUSs used to guide these procedures were not yet performed by personnel specialised in pulmonology, and in a 2016 survey carried out among resident pulmonology and internal medicine physicians, only $44 \%$ said they routinely used LUS to perform thoracentesis [11].

In other recently introduced examinations, such as the diagnosis and follow-up of SARS-CoV2 pneumonia, LUS was used by $27.8 \%$ of the centres in this study, with no difference between the complexity of the centres. These results are lower than those obtained by the Academy of Thoracic Ultrasound [12] in Italy, who reported that $60.2 \%$ and $63.4 \%$ of their survey respondents used LUS for diagnosing and following up this pathology, respectively. However, this study was subject to selection bias, because the study cohort comprised clinicians with a special interest in LUS. Moreover, up to $14.6 \%$ of respondents started using LUS because of the COVID19 pandemic, thanks to the increased availability of equipment and training (through webinars, video tutorials, and local teaching programs) at the time. Thus, these two factors were key pillars in the development of this technique.

A 2018 study from Italy which attempted to clarify the main difficulties in establishing the regular use of LUS, found that a lack of ultrasound scanners (52\%) and a deficit in training (22\%) were the main barriers to more common use of the technique [13]. However, current accessibility to ultrasound scanners in our specific environment should favour the adequate development of this technique given that only $5.7 \%$ of the centres we surveyed did not have access to this equipment. Notwithstanding, this current work highlighted the need to improve the provision of global training in ultrasound, especially for new diagnostic techniques and for the evaluation of the heart, lower limbs, and vocal cords. Both in the Italian study and in the present one carried out in Spain, the most explored pathology by LUS was pleural effusion; however, in the Italian group, there is evidence of a higher degree of development of LUS for evaluation of pneumonia (55\% vs. $30.7 \%$ ), which could be justified by the inclusion, in the Italian survey, of personnel belonging not only to pulmonology but also to internal medicine or intensive care [13].

The continuous development of new and more complex ultrasound modalities, such as elastography [14, 15], means that more focussed training will be required to ensure adequate implementation of these techniques in clinical practice. Although the use of LUS appears in the postgraduate training program in pulmonology, the learning curve necessary to identify different pathologies is not well accounted for in this program. Proficiency in LUS is often developed at the bedside in clinical environments while supervised by a more experienced operator, or in specific training courses with simulation systems to acquire theoretical-practical knowledge [16]. LUS is not associated with any complications from the ultrasound technique, but clinical decisions made based on LUS mean that it is vital to professionally train operators to achieve high levels of diagnostic precision. Thus, to regulate and ensure training in LUS, the BTS published five levels of training in four main modalities, emergencies, basic, advanced, and expert [17], ranging from an initial degree as an observer to an expert level with permission to supervise and train other professionals. All pulmonologists in training must reach the basic level and can go on to complete the advanced levels, while the expert level would be assigned to people specifically specialised in ultrasound; in our sample this corresponded to only $5.7 \%$ of the population (Table 1).

Regarding organisational and infrastructural factors, with respect to low-complexity hospitals, LUS tended to be performed only in the bronchopleural procedures area in high and intermediate-complexity centres $(6.15 \%$ vs. $31 \%$ and $36.6 \%$, respectively). However, of note, a significantly wider range of techniques, such as the evaluation of DVT, were carried out in low-complexity centres ( $56.2 \%$ vs. $20.6 \%$ and $23.3 \%$, respectively), perhaps because more complex centres are more subspecialised.

Only $20.1 \%$ of the surveyed centres taught accredited courses, with this figure being slightly higher than for high-complexity centres. Regarding research, there were very few institutional or multicentre projects being carried out in relation to ultrasound. Thus, we consider this as another objective for improvement, because such research translates into improvement of the quality of care, which is both a corporate and healthcare provision goal.

The limitations of this current study included the low percentage of professionals included that belonged to 


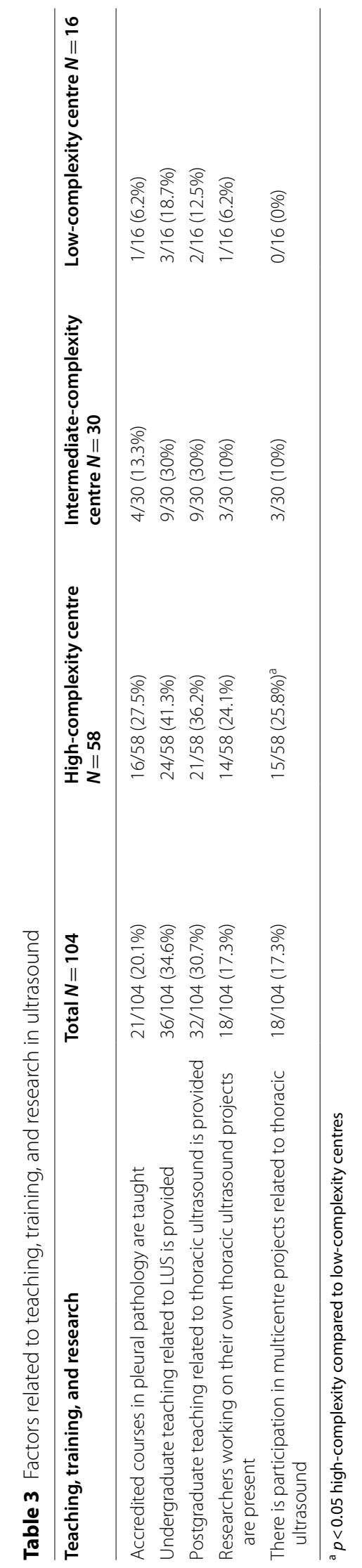


low-complexity centres, the lack of stratification by autonomous communities, which prevented us from performing an analysis of variability between territories, and that possible areas of development of LUS, such as consultations or critical units, have not been included. However, in our opinion, the analysed sample was sufficient to reflect how LUS is currently used in Spain and allowed us to establish recommendations for the better management of these processes. At the national level, other research groups have developed surveys to investigate the use of LUS in other prevalent pathologies, such as COPD [18], for the management of pleural effusion $[7,11]$ or in palliative care units [19]. We believe this type of analysis is required to develop new strategic lines of research through scientific societies, because ultrasound could be used to internally evaluate the quality of healthcare provision in different services, develop guidelines to improve the quality of care, promote the development of training, and to facilitate comparative studies between different hospitals.

\section{Conclusions}

Ultrasound is a tool whose use has increased in recent years, not only in bronchopleural procedure units, but also in the context of conventional ward hospitalisation, intermediate care units, and consultations. In parallel, the availability of ultrasound machines in pneumology services has also increased as a result of the clear advantages of this technique, which is why it seems necessary to gradually implement ultrasound as the fifth pillar of the physical examination of every type of pulmonary pathology. Nonetheless, this implies that pulmonologists must complete training to acquire advanced knowledge in this technique.

\section{Abbreviations}

BTS: British Thoracic Society; COVID-19: Coronavirus disease; DVT: Deep vein thrombosis; EBUS: Endobronchial ultrasound; EU: Europe; ILD: Interstitial lung disease; LVEF: Left ventricular ejection fraction; LL: Lower limb; LUS: Lung ultrasound; MIRs: Medical intern residents; SEPAR: Spanish Society of Pulmonology and Thoracic Surgery; SWE: Shear wave; TAPSE: Tricuspid annular plane systolic excursion.

\section{Acknowledgements}

SEPAR integrated research programs (PII) in interventional pulmonology. SEPAR techniques and transplantation area.

\section{Authors' contributions}

CR-H: conceptualization, methodology, software, validation, formal analysis, writing - original draft and project administration, and final approval of the version to be submitted; MB-R: methodology, validation, formal analysis, writing - review and editing, supervision, and final approval of the version to be submitted; RC-P: resources, software, data curation, and final approval of the version to be submitted, MN-D: data curation and final approval of the version to be submitted; AF-V: investigation, validation, supervision, and final approval of the version to be submitted. All authors read and approved the final manuscript.

\section{Funding}

This research did not receive any specific grant from funding agencies in the public, commercial, or not-for-profit sectors.

\section{Availability of data and materials}

The data sets used and/or analysed during the current study are available from the corresponding author on reasonable request.

\section{Declarations}

Ethics approval and consent to participate

Not applicable.

\section{Consent for publication}

Not applicable.

\section{Competing interests}

The authors declare that they have no competing interests.

\section{Author details}

${ }^{1}$ Department of Pneumology, Hospital Alvaro Cunqueiro, Neumo Vigo I + I. Institute of Health Research Galicia South (IISGS), Xerencia de Xestión integrada de Vigo, C/Clara Campoamor 341, 36312 Vigo, Pontevedra, Spain. ${ }^{2}$ Department of Pneumology, University Hospital of Salamcanca, P.o de San Vicente, 182, 37007 Salamanca, Spain.

Received: 10 March 2021 Accepted: 16 August 2021

Published online: 24 August 2021

\section{References}

1. Villena Garrido V, Cases Viedma E, Fernández Villar A, de Pablo GA, Pérez Rodríguez E, Porcel Pérez JM et al (2014) Normativa sobre el diagnóstico y tratamiento del derrame pleural. Actualización Arch Bronconeumol 50(6):235-249

2. Pallarés JPC. Manual de procedimientos SEPAR: Ecografía torácica. www. separ.es. Accessed 10 Jan 2021

3. Lichtenstein DA (2015) BLUE-protocol and FALLS-protocol: two applications of lung ultrasound in the critically ill. Chest 147(6):1659-1670

4. Kearon C, Ginsberg JS, Hirsh J (1998) The role of venous ultrasonography in the diagnosis of suspected deep venous thrombosis and pulmonary embolism. Ann Intern Med 129(12):1044-1049

5. Kumar A, Sinha C, Singh AK, Bhadani UK (2017) Vocal cord dysfunction: ultrasonography-aided diagnosis during routine airway examination. Saudi J Anaesth 11(3):370-371

6. Labovitz AJ, Noble VE, Bierig M, Goldstein SA, Jones R, Kort S et al (2010) Focused cardiac ultrasound in the emergent setting: a consensus statement of the American society of echocardiography and American college of emergency physicians. J Am Soc Echocardiogr 23(12):1225-1230

7. Botana-Rial M, Núñez-Delgado M, Leiro-Fernández V, Fernández-Villar A (2019) Resultados de una encuesta nacional sobre la situación actual del manejo del derrame pleural. Arch Bronconeumol 55(5):274-276

8. Lamont T, Surkitt-Parr M, Scarpello J, Durand M, Hooper C, Maskell N (2009) Safety alerts insertion of chest drains: summary of a safety report from the National Patient Safety Agency. BMJ 339:b4923

9. Havelock T, Teoh R, Laws D, Gleeson F, on behalf of the BTS (2010) Pleural disease guideline group. Pleural procedures and thoracic ultrasound: British thoracic society pleural disease guideline 2010. Thorax 65(Suppl 2):61-i76

10. De Lucas Ramos P, Rodríguez-Moro JM. Libro Blanco. La Neumología en España. Respira. Fundación Española del Pulmón. SEPAR; 2015. 11

11. Porcel JM, Cases-Viedma E, Bielsa S (2016) Una encuesta a médicos residentes sobre la realización de toracocentesis diagnósticas y terapéuticas: ¿una laguna en la formación? Rev Clin Esp 216(9):474-480

12. Zanforlin A, Tursi $F$ (2021) How is COVID-19 changing lung ultrasound? A survey by the thoracic ultrasound academy. J Ultrasound Med 40(2):417-418 
13. Zanforlin A, Tursi F, Marchetti G, Pellegrino G, Vigo B, Smargiassi A et al (2020) Clinical use and barriers of thoracic ultrasound: a survey of Italian pulmonologists. Respiration 99(2):171-176

14. Zhou B, Bartholmai BJ, Kalra S, Osborn TG, Zhang X (2019) Lung US surface wave elastography in interstitial lung disease staging. Radiology 291(2):479-484

15. Jiang B, Li X, Yin Y, Zhang Q, Zang T, Song W et al (2019) Ultrasound elastography: a novel tool for the differential diagnosis of pleural effusion. Eur Respir J 54(2):1802018

16. Laursen CB, Clive A, Hallifax R, Pietersen PI, Asciak R, Davidsen JR et al (2020) European respiratory society statement on thoracic ultrasound. Eur Respir J. https://doi.org/10.1183/13993003.01519-2020

17. Stanton AE, Edey A, Evison M, Forrest I, Hippolyte S, Kastelik J et al (2020) British thoracic society training standards for thoracic ultrasound (TUS). BMJ Open Resp Res 7:e000552

18. Calle Rubio M, Rodríguez Hermosa JL, Miravitlles M, López-Campos JL (2020) Conocimiento de la enfermedad pulmonar obstructiva crónica, presencia de síntomas respiratorios crónicos y uso de la espirometría en la población española: estudio CONOCEPOC 2019. Arch Bronconeumol s0300-2896(20):30271-30274
19. Barril S, Alonso A, Rodríguez-Portal JA, Viladot M, Giner J, Aparicio F et al (2018) Cuidados paliativos en la enfermedad pulmonar intersticial difusa: resultados de una encuesta de ámbito nacional. Arch Bronconeumol 54(3):123-127

\section{Publisher's Note}

Springer Nature remains neutral with regard to jurisdictional claims in published maps and institutional affiliations.

\section{Submit your manuscript to a SpringerOpen ${ }^{\circ}$ journal and benefit from:}

- Convenient online submission

- Rigorous peer review

- Open access: articles freely available online

- High visibility within the field

- Retaining the copyright to your article

Submit your next manuscript at $\boldsymbol{\nabla}$ springeropen.com 